\title{
Risk Factors and Outcomes for Retinopathy of Prematurity in Neonatal Infants with a Birth Weight of 1,501-2,000 $\mathrm{g}$ in a Chinese Neonatal Unit
}

\author{
Mei-Hong Gu ${ }^{a}$ Ji Jin ${ }^{a}$ Tian-Ming Yuan ${ }^{b}$ Hui-Min Yu ${ }^{b}$ \\ a Departments of Ophthalmology and Neonatology, Children's Hospital, Zhejiang University School of Medicine, \\ and ${ }^{b}$ Zhejiang Key Laboratory for Diagnosis and Therapy of Neonatal Disease, Hangzhou, China
}

\section{Key Words}

Retinopathy of prematurity - Retinopathy of prematurity, risk factor $\cdot$ Birth weight

\begin{abstract}
Objective: To determine the risk factors and outcomes of retinopathy of prematurity (ROP) in infants with a birth weight of 1,501-2,000 g. Materials and Methods: Clinical characteristics and risk factors were compared and nonconditional logistic regression analysis was performed to determine independent predictors for ROP. Results: There were $54(9.8 \%)$ cases of ROP in 553 patients with a birth weight of $1,501-2,000 \mathrm{~g}$. The most common classification of ROP was in stage 1 (50/54, 92.6\%; stages 2 and 3 ROP: 2 infants each). By logistic regression analysis, the following factors independently predicted ROP: gestational age at birth $\leq 34$ weeks [odds ratio (OR): 9.01; 95\% confidence interval (Cl): 1.18-68.70], septicemia (OR: 2.88; 95\% Cl: 1.30-6.36) and perinatal asphyxia (OR: $5.74 ; 95 \% \mathrm{Cl}: 2.35-14.01$ ). Conclusion: ROP occurred commonly among infants with a birth weight of 1,501-2,000 g. The risk factors were gestational age at birth $\leq 34$ weeks, septicemia and perinatal asphyxia.
\end{abstract}

Copyright $\odot 2011$ S. Karger AG, Basel

\section{KARGER}

Fax +4161306 1234

E-Mail karger@karger.ch

www.karger.com
(C) 2011 S. Karger AG, Basel

1011-7571/11/0203-0244\$38.00/0

Accessible online at:

www.karger.com/mpp

\section{Introduction}

Retinopathy of prematurity (ROP) is a retinal vascular disorder frequently seen in very premature infants and is associated with poor clinical outcomes. An evaluation of ROP screening guidelines in developing countries demonstrates that some infants are missed, most of whom are more 'mature' [1]. Hence, the application of western screening guidelines for developing countries has been questioned by some researchers [2], and local information is required to identify the at-risk population in each area.

The epidemiology and outcomes of ROP are well described in very-low-birth-weight (VLBW) preterm infants, especially in infants with a birth weight (BW) $<1,251 \mathrm{~g}$ [3], but scant data exist for infants with a BW $>1,500 \mathrm{~g}$, particularly with respect to risk factors and outcomes such as morbidity and hospital length of stay. In 2002, a Swedish study reported that of those infants weighing less than $750 \mathrm{~g}, 95.3 \%$ developed ROP, while $65.7 \%$ of those with a BM of 751-1,000 g developed ROP, $17.5 \%$ of those with a BM of $1,001-1,500 \mathrm{~g}$ developed ROP, and $5.4 \%$ of those with a BW $>1,500$ g developed the disease [4]. The estimated incidence of ROP in VLBW pa- 
tients in developing countries was reported to be $21.7 \%$ [5]. Many risk factors for the development of ROP in VLBW infants have been identified including low BW, low gestational age, supplemental oxygen therapy following delivery and multiple births [6-9], and many others $[9,10]$.

Preterm infants with a BW $>1,500$ g may have different underlying illnesses, and undergo different medical procedures than do VLBW infants [11]. Because preterm infants with a BW $>1,500 \mathrm{~g}$ are different from VLBW infants, specific studies of the risk factors and outcomes of ROP should be performed. Recently, Lad et al. [12] described the epidemiology of ROP among premature infants with a length of stay of more than 28 days in the USA and Slidsborg et al. [13] reported that the incidence of ROP treatment was $2.5 \%$ in the premature infants with a gestational age of $<32$ weeks in Denmark. However, there is limited data with respect to the risk factors and outcomes specific to ROP from premature infants with a $\mathrm{BW}>1,500 \mathrm{~g}$. We studied neonates with a $\mathrm{BW}>1,500 \mathrm{~g}$ to determine risk factors for ROP and the impact of ROP on preterm infants.

\section{Subjects and Methods}

\section{Patients}

In our neonatal intensive care unit, infants were examined according to the Chinese Ministry of Health Guidelines [14]. All neonates admitted to the neonatal intensive care unit in 20052008 with a BW between 1,500 and 2,000 g were included in the study. The study population was divided into two clinical groups: ROP and control.

\section{Screening Methodology}

All infants with a gestational age of 32-34 weeks were examined regularly by experienced ophthalmologists at 1- to 2-week intervals. They were excluded if the examinations were stopped too early, before the retina was completely vascularized, or started too late (i.e., after full vascularization or more than 8 weeks after birth). The eyes were dilated with a combination of cyclopentolate $0.5 \%$ and phenylephrine $0.5 \%$ drops. Indirect ophthalmoscopy with a 20- to 30-dpt lens was performed. If the border between vascularized and unvascularized retina could not be seen, we used a lid speculum and indentation. In eyes in which ROP was observed, the location and severity were recorded and the stage of ROP was also diagnosed according to the ICROP [15]. Examinations were conducted at least every 2 weeks after ROP was first seen.

\section{Risk Factor Analysis}

Patient demographics, underlying disease, procedures, and medications were registered. The incidence of ROP was studied by multiple regression analysis of relevant factors: gestational age, birth weight, sex, multiple births, small for gestational age, oxy-

Risk Factors and Outcomes for

Retinopathy of Prematurity gen therapy and underlying disease such as respiratory distress syndrome, apnea, septicemia, hypoglycemia and perinatal asphyxia.

Gestational age was defined by the neonatalogist caring for the patient and was based on obstetric data including early ultrasound findings and menstrual history when available or physical examination findings at the time of birth. A cutoff of 34 weeks of gestational age at birth was used because it corresponded to the median time of occurrence of ROP in our data, and because gestational age at 34 weeks or less was associated with increased likelihood of occurrence of ROP. Apnea was defined as cessation of respiratory flow for $>20 \mathrm{~s}$ or associated with bradycardia. Small for gestational age was defined as BW below the 10th percentile for the gestational age. Oxygen therapy was defined as either no oxygen administered or the use of supplemental oxygen, whether continuous or intermittent oxygen therapy.

\section{Statistical Analysis}

The odds ratio (OR) associated with a given factor was an estimate of the risk of ROP when the factor was present as opposed to when it was absent; 95\% confidence intervals (95\% CIs) were used as a measure of the statistical precision of each OR. Adjustment for other confounding variables was also made by multiple forward stepwise logistic regression analysis. Comparisons of data were made by the $\chi^{2}$ test or Student's t test as appropriate. $\mathrm{p}<0.05$ was considered statistically significant.

\section{Results}

During the 4-year study period, complete eye examination data were available of 951 infants, including 398 infants with a BW of 700-1,500 $\mathrm{g}$ and 553 infants with a BW of 1,501-2,000 g. The incidence of ROP was $38.5 \%$ (15/39) in infants with a BW of $700-1,000 \mathrm{~g}, 10.6 \%(38 / 359)$ in infants with a BW of 1,001-1,500 $\mathrm{g}$ and $9.8 \%(54 / 553)$ in infants with a BW of 1,501-2,000 g.

Among the 54 infants with a BW of 1,501-2,000 g with ROP, stage 1 ROP was found in 50/54 (92.6\%). Two infants developed stage 2 ROP and another 2 infants developed stage 3 ROP. All the cases of stage 1 and stage 2 ROP regressed without treatment, while the 2 infants with stage 3 ROP underwent laser treatment because they were classified as having zone I stage $3 \mathrm{ROP}$, and our treatment criteria were: (1) zone I, any ROP with plus disease, (2) zone I, stage 3 without plus disease, (3) zone II, stage 3 with plus disease. Moreover, all 54 ROP infants did not have plus disease.

In infants with a BW of 1,501-2,000 g with ROP, the mean gestational age at birth was $32.4 \pm 1.6$ weeks (range: 28-37 weeks, median: 32.8 weeks). Stage 1 ROP had a gestational age at birth of 28-34 weeks. Patients with ROP did not have a lower BW than infants without ROP $(1,809.2 \pm 140.6 \mathrm{~g}$ vs. $1,788.6 \pm 142.5 \mathrm{~g}, \mathrm{p}>0.05)$. 
Table 1. Comparison of infants with and without ROP

\begin{tabular}{|c|c|c|c|}
\hline & $\begin{array}{l}\text { ROP } \\
(\mathrm{n}=54)\end{array}$ & $\begin{array}{l}\text { No ROP } \\
(\mathrm{n}=499)\end{array}$ & $\begin{array}{l}\mathrm{p} \\
\text { value }\end{array}$ \\
\hline $\begin{array}{l}\text { Gestational age at } \\
\text { birth, weeks }\end{array}$ & $32.4 \pm 1.6$ & $32.5 \pm 1.9$ & $<0.65$ \\
\hline BW, g & $1,809.2 \pm 140.6$ & $1,788.6 \pm 142.5$ & 0.31 \\
\hline \multicolumn{4}{|l|}{ Sex } \\
\hline Male & $35(64.8 \%)$ & $313(62.7 \%)$ & \multirow[t]{2}{*}{0.76} \\
\hline Female & $19(35.2 \%)$ & $186(37.3 \%)$ & \\
\hline \multicolumn{4}{|c|}{ Gestational age at birth $\leq 34$ weeks } \\
\hline No & $1(1.9 \%)$ & $58(11.6 \%)$ & \multirow[t]{2}{*}{0.03} \\
\hline Yes & $53(98.1 \%)$ & $441(88.4 \%)$ & \\
\hline \multicolumn{4}{|l|}{ Multiple births } \\
\hline No & $43(79.6 \%)$ & $443(88.8 \%)$ & \multirow[t]{2}{*}{0.05} \\
\hline Yes & $11(20.4 \%)$ & $56(11.2 \%)$ & \\
\hline \multicolumn{4}{|l|}{ SGA } \\
\hline No & $54(100.0 \%)$ & $481(96.4 \%)$ & \multirow[t]{2}{*}{0.16} \\
\hline Yes & $0(0.0 \%)$ & $18(3.6 \%)$ & \\
\hline \multicolumn{4}{|l|}{ Oxygen therapy } \\
\hline No & $41(75.9 \%)$ & $329(65.9 \%)$ & \multirow[t]{2}{*}{0.14} \\
\hline Yes & $13(24.1 \%)$ & $170(34.1 \%)$ & \\
\hline \multicolumn{4}{|l|}{ RDS } \\
\hline No & $44(81.5 \%)$ & $421(84.4 \%)$ & \multirow[t]{2}{*}{0.58} \\
\hline Yes & $10(18.5 \%)$ & $78(15.6 \%)$ & \\
\hline \multicolumn{4}{|l|}{ Apnea } \\
\hline No & $53(98.1 \%)$ & $482(96.6 \%)$ & \multirow[t]{2}{*}{0.54} \\
\hline Yes & $1(1.9 \%)$ & $17(3.4 \%)$ & \\
\hline \multicolumn{4}{|l|}{ Septicemia } \\
\hline No & $44(81.5 \%)$ & $459(92.0 \%)$ & \multirow[t]{2}{*}{0.01} \\
\hline Yes & $10(18.5 \%)$ & $40(8.0 \%)$ & \\
\hline \multicolumn{4}{|l|}{ Hypoglycemia } \\
\hline No & $52(96.3 \%)$ & $488(97.8 \%)$ & \multirow[t]{2}{*}{0.49} \\
\hline Yes & $2(3.7 \%)$ & $11(2.2 \%)$ & \\
\hline \multicolumn{4}{|l|}{ Perinatal asphyxia } \\
\hline No & $45(83.3 \%)$ & $479(96.0 \%)$ & \multirow[t]{2}{*}{$<0.01$} \\
\hline Yes & $9(16.7 \%)$ & $20(4.0 \%)$ & \\
\hline \multicolumn{4}{|l|}{ Hospital length } \\
\hline of stay, days & $14.5 \pm 4.0$ & $13.9 \pm 4.7$ & 0.36 \\
\hline
\end{tabular}

SGA = Small for gestational age; RDS = respiratory distress syndrome.

Table 2. Multinomial nonconditional logistic regression analysis

\begin{tabular}{lllll}
\hline Factors & $\begin{array}{l}\beta \text { coeffi- } \\
\text { cient }\end{array}$ & OR & $95 \%$ CI & $\begin{array}{l}\mathrm{p} \\
\text { value }\end{array}$ \\
\hline $\begin{array}{l}\text { Gestational age at } \\
\quad \text { birth } \leq 34 \text { weeks }\end{array}$ & 2.20 & 9.01 & $1.18-68.70$ & 0.034 \\
$\begin{array}{l}\text { Septicemia } \\
\text { Perinatal asphyxia }\end{array}$ & 1.06 & 2.88 & $1.30-6.36$ & 0.009 \\
Multiple births & 1.75 & 5.74 & $2.35-14.01$ & 0.001 \\
\hline
\end{tabular}

Univariate analysis comparing infants whose BW ranged from 1,501 to $2,000 \mathrm{~g}$ with and without ROP is summarized in table 1. ROP was correlated with the following factors: gestational age at birth $\leq 34$ weeks, septicemia, perinatal asphyxia and multiple births. After multivariate analysis, only gestational age at birth $\leq 34$ weeks, septicemia and perinatal asphyxia remained significantly associated with ROP in the forward stepwise logistic regression model (table 2).

\section{Discussion}

The incidence of ROP of $9.8 \%$ in our study is higher than that (5.4\%) reported by Larsson and Holmström [4] probably because the screening criteria were BW $\leq 2,000 \mathrm{~g}$, being much wider than those recommended for use in the USA ( $\leq 1,500 \mathrm{~g}$ or $\leq 28$ weeks) [16] and the UK $(\leq 1,500 \mathrm{~g}$ and $\leq 31$ weeks) [17]. These wider criteria were applied to avoid missing any severe disease. If we had used narrower criteria, 2 infants with severe ROP (stage 3) needing treatment would have been missed.

Risk factors for ROP offer prognostic information about the probability of developing the disease, may lead to the development of effective prevention, and may allow risk stratification to target high-risk patients for screening strategies. Prematurity is the main causal factor, as demonstrated by the widely proven correlation between the incidence and severity of ROP and gestational age [18, 19], and gestational age was also reported to be the dominant risk factor for severe ROP [20]. Our results suggested that the group of patients with a BW of 1,501-2,000 g with ROP did not have lower gestational age compared to the patients without ROP, but we found that if gestational age at birth was $\leq 34$ weeks, the risk of ROP in the patients with a BW of 1,501-2,000 g was increased by 9-fold. Thus, these results suggested that whether or not the BW was less than $1,500 \mathrm{~g}$, screening guidelines might include any infants whose gestational age at birth was $\leq 34$ weeks. Another unique risk factor that we identified was perinatal asphyxia. The low scores in the Apgar test have been described as a risk factor in a study by García-Serrano et al. [21]. Moreover, infants with cerebral palsy who have a higher incidence of retinal vascular anomalies were also associated with both cerebral ischemia and prematurity [22].

However, there were several limitations in our study. First, this single-center study might result in misinterpretation of the incidence of ROP in the general population of infants with a BW of 1,501-2,000 $\mathrm{g}$ in China. In addi- 
tion, the sample size and the small number of events per group, as well as the retrospective study design substantially limit our conclusions. Therefore, a large and prospective randomized controlled trial is required and studies of interventions such as control perinatal septicemia and decreasing perinatal asphyxia might be achievable.

\section{Conclusion}

Our study showed a relatively high rate of ROP and the identified independent predictors of ROP included gestational age at birth $\leq 34$ weeks, septicemia and perinatal asphyxia.

\section{References}

1 Vinekar A, Dogra MR, Sangtam T, Narang A, Gupta A: Retinopathy of prematurity in Asian Indian babies weighing greater than $1,250 \mathrm{~g}$ at birth: ten year data from a tertiary care center in a developing country. Indian J Ophthalmol 2007;55:331-336.

-2 Jalali S, Anand R, Kumar H, Dogra MR, Azad RV, Gopal L: Programme planning and screening strategy in retinopathy of prematurity. Indian J Ophthalmol 2003;51:89-99.

3 Good WV, Hardy RJ, Dobson V, Palmer EA, Phelps DL, Quintos M, Tung B, Early Treatment for Retinopathy of Prematurity Cooperative Group: The incidence and course of retinopathy of prematurity: findings from the early treatment for retinopathy of prematurity study. Pediatrics 2005;116:15-23.

4 Larsson E, Holmström G: Screening for retinopathy of prematurity: evaluation and modification of guidelines. $\mathrm{Br} \mathrm{J}$ Ophthalmol 2002;86:1399-1402.

5 Sharma R, Gupta VP, Dhaliwal U, Gupta P: Screening for retinopathy of prematurity in developing countries. J Trop Pediatr 2007;53: 52-54.

6 Leo SW, Cheong PY: Incidence of retinopathy of prematurity in Singapore. Singapore Med J 1997;38:54-57.

7 Arrøe M, Peitersen B: Retinopathy of prematurity: review of a seven-year period in a Danish neonatal intensive care unit. Acta Paediatr 1994;83:501-505.

8 Bergh T, Ericson A, Hillensjö T, Nygren KG, Wennerholm UB: Deliveries and children born after in-vitro fertilisation in Sweden 1982-1995: a retrospective cohort study. Lancet 1999;354:1579-1585.
9 Seiberth V, Linderkamp O: Risk factors in retinopathy of prematurity: a multivariate statistical analysis. Ophthalmologica 2000; 214:131-135.

10 Wheatley CM, Dickinson JL, Mackey DA, Craig JE, Sale MM: Retinopathy of prematurity: recent advances in our understanding. Arch Dis Child Fetal Neonatal Ed 2002; 87:F78-F82.

11 Ma X, Huang C, Lou S, Lv Q, Su W, Tan J, Wang Y, Wang X, Wu M, Xu T, Zhuang M, Du L: Provincial collaborative study group for late-preterm infants. The clinical outcomes of late preterm infants: a multi-center survey of Zhejiang, China. J Perinat Med 2009;37:695-699.

12 Lad EM, Hernandez-Boussard T, Morton JM, Moshfeghi DM: Incidence of retinopathy of prematurity in the United States: 1997 through 2005. Am J Ophthalmol 2009;148: 451-458.

13 Slidsborg C, Olesen HB, Jensen PK, Jensen $H$, Nissen KR, Greisen G, Rasmussen S, Fledelius HC, la Cour M: Treatment for retinopathy of prematurity in Denmark in a ten-year period (1996-2005): is the incidence increasing? Pediatrics 2008;121:97-105.

14 Chinese Medical Association: Guidelines on oxygenation policies and on prevention and treatment of retinopathy of prematurity. Zhonghua Yan Ke Za Zhi 2005;41:375-376.
15 International Committee for the Classification of Retinopathy of Prematurity: The international classification of retinopathy of prematurity revisited. Arch Ophthalmol 2005;123:991-999.

16 American Academy of Pediatrics. Section on Ophthalmology: Screening examination of premature infants for retinopathy of prematurity. Pediatrics 2001;108:809-811.

17 Wilkinson AR, Haines L, Head K, Fielder AR: UK retinopathy of prematurity guideline. Early Hum Dev 2008;84:71-74.

18 Giannantonio C, Papacci P, Molle F, Lepore D, Gallini F, Romagnoli C: An epidemiologic analysis of retinopathy of prematurity over 10 years. J Pediatr Ophthalmol Strabismus 2008;45:162-167.

19 Liu PM, Fang PC, Huang CB, Kou HK, Chung MY, Yang YH, Chung CH: Risk factors of retinopathy of prematurity in premature infants weighing less than 1,600 g. Am J Perinatol 2005;22:115-120.

20 Darlow BA, Hutchinson JL, HendersonSmart DJ, Donoghue DA, Simpson JM, Evans NJ, Australian and New Zealand Neonatal Network: Prenatal risk factors for severe retinopathy of prematurity among very preterm infants of the Australian and New Zealand neonatal network. Pediatrics 2005;115: 990-996.

-21 García-Serrano JL, Ramírez-García MC, Pinar-Molina R: Retinopathy of prematurity in multiple births: risk analysis for plus disease. Arch Soc Esp Oftalmol 2009;84:191-198.

22 Pennefather PM, Tin W: Ocular abnormalities associated with cerebral palsy after preterm birth. Eye 2000;14:78-81. 